\title{
Р.Б. Беков
}

\section{ЭФФЕКТИВНОСТЬ МЕХАНИЗМОВ ИННОВАЦИОННОГО РАЗВИТИЯ ЭКОНОМИКИ РФ}

\begin{abstract}
В статье рассмотрены основные государственные институты развития в РФ, ответственные за процессы внедрения инновачий и технологическую модернизаиию экономики. Приведена экспертная оценка экономического состояния России по итогам работы крупнейших международных экономических форумов 2016 г. в Давосе и Санкт-Петербурге с учетом мировых трендов и вызовов. Также дана оценка текущего состояния инвестиционной привлекательности российской экономики. Определено место Российской Федерации в рейтинге глобальной конкурентоспособности. Автором проведен анализ деятельности государственных институтов развития, таких как Федеральное агентство стратегических инициатив, АO «Российская венчурная компания», ОАО «Роснано», Внешэкономбанк. Осуществлен сравнительный анализ экономической и соииальной эффективности функиионирования фондов инновационного развития. В частности, рассмотрена деятельность фонда «Сколково» и Фонда содействия развитию мальх форм предприятий в научно-технической сфере. По результатам проведенного анализа даны некоторые рекомендации по совершенствованию государственных механизмов инновачионного развития.

Ключевые слова: Всемирный экономический форум, индекс глобальной конкурентоспособности, Агентство стратегических инициатив, Внешэкономбанк, фонд «Сколково», инновационное развитие экономики, эффективность, инвестиции.
\end{abstract}

В 2016 г. прошли два крупнейших мировых экономических форума: 46-й Всемирный экономический форум (ВЭФ) в Швейцарии в Давосе (2023 января) и 20-й Петербургский международный экономический форум (16-18 июня). Экспертами были озвучены основные тренды развития глобальной экономической системы, которые бросают вызовы национальным экономикам.

Аналитической группой Всемирного экономического форума ежегодно публикуется рейтинг конкурентоспособности национальных экономик.

В исследовании ВЭФ представлены два индекса, на основе которых составляются рейтинги стран: индекс глобальной конкурентоспособности (Global Competitiveness Index, GCI) и индекс конкурентоспособности бизнеса (Business Competitiveness Index, BCI).

По мнению экспертов ВЭФ, ведущие страны мира ищут источники роста в использовании и капитализации колоссального технологического потенциала, который уже имеется и продолжает формироваться. Происходит взрывной рост производительности труда, что неизбежно приведет к реструктуризации целых отраслей, обесценятся многие произ- 
водства и активы, изменится спрос на профессии и компетенции, обострится и конкуренция как на традиционных, так и на формирующихся рынках.

К сильным сторонам российской экономики эксперты форума также отнесли высокую распространенность высшего образования, развитие инфраструктуры, улучшение показателей бизнес-регулирования.

Однако воспользоваться своими конкурентными преимуществами России мешают низкая эффективность работь государственных институтов, недостаточный уровень использования инновационного потенциала, слабая развитость финансового рынка и дефицит доверия инвесторов к финансовой системе. В последние два года к указанным отрицательным факторам добавились ослабление внутреннего спроса, экономические санкции со стороны стран Северной Америки и Западной Европы, а также внешняя неопределенность относительно будущего цен на минеральные ресурсы.

Ключевыми проблемами для экономического развития в России представители бизнеса называют коррупцию, неэффективность государственного аппарата, высокие налоговые ставки. Все эти факторы способствуют неэффективному распределению ресурсов страны и препятствуют росту конкурентоспособности.

В то же время, по мнению российских экспертов, ведущие в технологическом отношении державы проводят стратегию монополизации технологий, искусственно создавая закрытые пространства посредством различного рода барьеров доступа к технологиям. Это позволяет увеличивать долю прибыли от использования инновационных технологий. Однако это отрицательно отражается на экономике менее развитых стран, еще больше увеличивая отрыв в уровне развития экономик. Такая стратегия отрицательно сказывается на состоянии глобальной социально-экономической и политической стабильности, поскольку большая разница в жизненном уровне развитых и развивающихся стран приводит к высокому уровню миграции населения из африканских и азиатских регионов в Европу и США [10].

Следствием данной стратегии является и применение различного рода экономических санкций против отдельных стран, в том числе и против России. Учитывая характер санкций, а это в основном касается высокотехнологичной продукции и самих инновационных технологий, очевидна основная цель данных санкций - затормозить диффузию инноваций в отдельных отраслях. Тем самым тормозится технологическое развитие экономики страны, что негативно отражается на производительности труда и глобальной конкурентоспособности государства [6. С. 274-275].

Эксперты Давосского форума отмечают, что дальнейший рост автоматизации повысит производительность оборудования, поэтому будет требоваться меньше инвестиций для производства того же самого или даже большего объема продукции в долгосрочной перспективе.

Хотя это, конечно, кажется положительным эффектом, однако в результате может привести к длительному снижению темпов экономического ро- 
ста в богатых экономиках - длительной стагнации. Таким образом, зажиточные домохозяйства продолжат накопление сбережений, а инвесторы будут инвестировать еще меньше, так как меныший объем капитала будет приносить больший доход при росте автоматизации. Это приведет к избыточной экономии, что, в свою очередь, вызовет снижение размера экономики [12].

Наиболее ярко данные процессы проявляются в экономике Китая, где имелась высокая степень использования ручного труда. Вследствие автоматизации экономический рост Китая начинает снижаться, и Китай тянет за собой все остальные развивающиеся рынки по снижающейся траектории. Так как спрос Китая на сырье, которое он использует для своей тяжелой промышленности и в строительстве, начинает снижаться, цены на сырье снизились до 10-летнего минимума.

Дальнейшее укрепление доллара означает проблемы для развивающихся экономик, у которых значительный объем долга номинирован в доллаpax на фоне более низких доходов от продажи сырья. Поскольку значительная доля российского экспорта связана с сырьем, то данная тенденция негативно сказывается и на росте экономики нашей страны [13].

Практически единственным способом решения данной проблемы является развитие новых отраслей для притока избыточных накоплений и, таким образом, расширения возможностей экономики.

Подводя итог двух крупнейших международных экономических форумов, прошедших в 2016 г. в Давосе и Санкт-Петербурге, можно сказать, что происходит резкое обострение конкуренции между государствами на глобальном уровне. Одними из проявлений данных процессов являются сговор и закрытые экономические союзы между ведущими державами, направленные против третьих стран-конкурентов; использование рычагов давления через международные организации на экономику стран с высоким уровнем потенциала с целью искусственного сдерживания их роста (ограничение экспорта-импорта, доступа к инвестициям и финансовым ресурсам, инновационным технологиям, природным ресурсам и т.д.) [2].

По оценкам международных экспертов, инновационный потенциал России очень высок, однако эффективность использования его слишком низкая. В сложившихся условиях Россия должна принять адекватные меры адаптации к факторам внешней среды. В первую очередь следует более эффективно использовать инновационный потенциал. Для реализации его необходима соответствующая государственная политика в области инновачионного развития экономики [7].

Требуется разъяснить, что под инновационным развитием понимается разработка и реализация мероприятий, выводящих экономику на новый качественный уровень, позволяющий значительно расширить ее потенциал и повысить конкурентоспособность на глобальном уровне [8].

Более высокий качественный уровень экономики означает рост реальных доходов населения, повышение качества жизни людей, более высокий уровень собираемости налогов и, как следствие, более широкую возможность реализации социальных и экологических программ и т.д. 
Реализуется инновационная политика через механизмы инновационного развития, в качестве которых выступают субъекты управления инновационными процессами. Субъектами управления инновационными процессами (институтами развития) в РФ являются: Парламент, Правительство, Федеральное агентство стратегических инициатив, АО «Российская венчурная компания», государственные фонды инновационного развития, OAO «Роснано», Внешэкономбанк.

Управление инновационными процессами происходит через инструменты развития, которыми являются акты и документы, принимаемые субъектами управления. Это в первую очередь законы, стратегии, целевые программы, бюджеты, решения.

Таким образом, от эффективности функционирования механизмов развития и использования инструментов управления зависит степень реализации инновационного потенциала экономики [4].

Для решения этих задач в РФ созданы и функционируют соответствующие институты развития. Проанализируем более подробно деятельность некоторых механизмов инновационного развития РФ [5. С. 29].

Федеральное агентство стратегических инициатив согласно уставу должно определять основные приоритетные направления развития экономики, т.е. фактически определять новые отрасли, предпочтительные для инвестирования. АО «Российская венчурная компания» должна способствовать притоку инвестиций в эти отрасли на этапе их зарождения. Таким образом, должно обеспечиваться сохранение высоких темпов роста экономики.

Фонд «Сколково», ОАО «Роснано», Внешэкономбанк и РВК относятся к так называемым институтам развития Российской Федерации, т.е. инструментам решения задач государства в рыночной среде.

$\boldsymbol{A O}$ «PBK» - государственный фонд фондов, институт развития Российской Федерации, один из ключевых инструментов государства в деле построения национальной инновационной системы. С 2015 г. РВК определена как проектный офис по реализации Национальной технологической инициативы (НТИ) - программы мер, нацеленной на формирование принципиально новых рынков и создание условий для глобального технологического лидерства России к 2035 г. Особое внимание РВК должна уделять наукоемким высокорисковым индустриальнылм секторам с низким присутствием частного капитала, которые важны для сбалансированного инновационного развития страны, а также перспективным межотраслевым сегментам [12].

Отраслевая структура рынка в 2015 г. выглядела следующим образом. По-прежнему лидирующую роль по общему объему инвестиций сохранил сектор ИТ и составил 88\%, однако сегменты промышленных технологий и биотехнологий в 2015 г. продемонстрировали уверенный рост и в сумме увеличили свой удельный вес до $12 \%$ [12].

Необходимо отметить, что данные сектора экономики не являются новыми, например, отрасль информационных технологий зародилась в 50-е гг. 
прошлого века и является достаточно зрелой. Поэтому, финансируя данную отрасль, РВК не совсем выполняет функцию создания новых отраслей.

Ниже приведем анализ эффективности функционирования государственных фондов инновационного развития экономики по некоторым показателям.

Фонд развития Центра разработки и коммерциализации новых технологий «Сколково» - некоммерческая организация, созданная по инициативе президента РФ Д.А. Медведева в сентябре 2010 г. [13].

Бюджет самого фонда «Сколково» на 2012 г. составлял 49 млрд руб., из них 42 млрд руб. - деньги из госбюджета: 37 млрд руб. - финансирование со стороны Минфина, 5 млрд руб. - субсидии от Федеральной таможенной службы на компенсацию таможенных пошлин компанийучастников. Оставшиеся 7 млрд руб. в бюджете фонда - минимальный уровень привлечения внебюджетных средств [14].

В 2012 г. фонд выдал гранты для компаний-разработчиков на общую сумму 3 млрд руб. из запланированных 6,3 млрд руб. Таким образом, целевое финансирование фонда составило 6\% от общего бюджета фонда (3 млрд руб. / 49 млрд руб. × 100\%).

По своей сути фонд «Сколково» должен поощрять в виде господдержки в первую очередь проекты, способствующие качественно новому развитию экономики страны. Основой такого изменения, безусловно, являются проекты, предлагающие новые альтернативные варианты добычи энергии, а именно без использования традиционных углеводородов. По сути, именно такой направленности проекты должны получать господдержку в первую очередь. Однако в реальности эксперты фонда на конкурсах отдают предпочтение проектам именно в нефтегазовой отрасли.

Как видно из вышеприведенной информации, вместо развития альтернативной энергетики фонд «Сколково» активно поддерживает традиционную энергетику, основанную на углеводородах и ядерном топливе, а также традиционные отрасли, которые принадлежат корпорациям, - это интернет-технологии и телекоммуникации, освоение околоземной орбиты, медицина и агротехнологии. Хотя в данных отраслях и имеются некоторые инновации, однако сами эти отрасли достаточно зрелые и не являются развивающимися. Как было отмечено, финансирование зрелых отраслей экономики не приведет к качественному скачку в экономике. Необходимы инвестиции в новые развивающиеся отрасли, например освоение дальнего космоса, бестопливная энергетика, альтернативные новые виды транспорта, освоение океанских глубин и т.п.

В структуре расходов фонда за 2013-2015 гг. (65 028,6 млн руб.) расходы по целевым направлениям составили:

- на «Создание и управление физической инфраструктурой ИЦ «Сколково» - 61,5\% (39 957,6 млн руб.) - фактически затраты на собственные нужды;

- «Создание и развитие инновационной среды» - 20,2\% (13 163,7 млн руб.);

- «Создание и развитие Сколковского института науки и технологии (Сколтех)» - 18,3\% (11 907,3 млн руб.) [21]. 
Одна из задач «Сколково» - грантовая поддержка научно-исследовательских проектов. За три года фонд потратил на это 4,8 млрд руб. - всего $7,4 \%$ от общей суммы своих расходов за счет субсидий из федерального бюджета.

По правилам фонда и эксперты, и члены грантового комитета должны отказываться от работы, если являются заинтересованными лицами, в том числе по отношению к грантополучателям. По данным Счетной палаты, заинтересованными в проектах лицами оказались почти $60 \%$ из 1188 экспертов и $30 \%$ из 15 членов грантового комитета [15].

Другой конкурс на грантовую поддержку инновационных проектов в сфере энергетики - это «Энергопрорыв-2016», организованный ПАО «Россети» в партнерстве с фондом «Сколково» и при поддержке Агентства стратегических инициатив, стартовал в 2013 г. В 2015 г. «Энергопрорыв» собрал более 170 проектов из 50 городов России.

Как известно, ПАО «Россети» является монополистом в области выработки, транспортировки и распределения электроэнергии в России, причем все это опять же традиционным старым способом, т.е. централизованно, при котором компания имеет возможность монопольно устанавливать тарифы на подключение и потребление электроэнергии в стране. Тогда как альтернативные источники электроэнергии предполагают независимость потребителя от кого-либо. Естественно организаторы данного конкурса ни в коей мере не заинтересованы в поддержке действительно инновационных разработок в области альтернативной энергетики.

Сделаем некоторые выводы по итогам деятельности государственных фондов развития, исходя из вышеприведенного анализа. Таким образом, фонд «Сколково» аккумулирует большие объемы государственных средств, однако эффективность их использования в целях инновационного развития очень низкая по следующим причинам:

- очень высокий процент средств потребляет фонд на собственные нужды, а не на гранты;

- финансируются не инновационные отрасли, а традиционные.

Вследствие вышеуказанного фонд «Сколково» не может быть эффективным механизмом инновационного развития экономики. В правлении фонда большое влияние имеют корпорации, которые в большинстве своем являются естественными монополистами в отдельных отраслях экономики и соответственно лоббируют свои интересы в фонде путем влияния на политику фонда.

Фонд содействия развитию малых форм предприятий в научнотехнической сфере - один из шести государственных научных фондов. В фонд направляется 1,5\% средств федерального бюджета, выделенного на науку. Основные задачи фонда - проведение государственной политики развития и поддержка малых предприятий в научно-технической сфере, оказание прямой финансовой и информационной помощи исследователям, реализующим проекты по разработке и освоению новых видов наукоемкой продукции и технологий, создание и развитие инфраструктуры поддержки 
малого инновационного предпринимательства. Фонд осуществляет финансовое обеспечение проектов на основе договоров (контрактов), а также путем предоставления грантов физическим и юридическим лицам на финансовое обеспечение проектов, в том числе проектов, результаты которых имеют перспективу коммерциализации [16].

Основная задача фонда в системе государственных институтов развития - создание максимально благоприятных условий для оптимизации потока качественных проектов и их дальнейшая поддержка другими структурами. Таким образом, фонд становится первым этажом «инновационного лифта». Партнерами в решении данной задачи являются Российская венчурная компания (РВК), Фонд посевных инвестиций РВК, «Роснано», фонд «Сколково», Внешэкономбанк (ВЭБ), Московская межбанковская валютная биржа (ММВБ), которые обладают своими ресурсами и включаются в финансирование предприятий на соответствующем этапе [16].

Согласно отчету расходы фонда на поддержку проектов составили всего: за 2014 г. 4103 740,4 млрд руб. (467,6 млрд руб. × 1,5\%= 7,014 млрд руб.), или $58,5 \%$ от целевого финансирования [17].

В 2015 г. бюджетные ассигнования фонда за счет средств федерального бюджета всего составили 8533 457,2 тыс. руб. Кассовые расходы фонда по выплатам за счет субсидий из средств федерального бюджета в 2015 г. осуществлены в сумме 8138 020,9 тыс. руб., что составило 79,7\% от поступлений 2015 г. с учетом переходящего остатка на 01.01.2015 и сумм возвратов дебиторской задолженности прошлых лет [18].

Таким образом, в 2015 г. Фонд Бортника показал большую эффективность в отношении целевого финансирования по сравнению с 2014 г. (79,7\% против 58,5\%).

Для определения относительной эффективности деятельности фондов инновационного развития РФ сравним их показатели с показателями государственного Пенсионного фонда. Так, на 2016 г. общий объем бюджета Пенсионного фонда РФ составил 7703901 279,5 тыс. руб., а объем бюджетных ассигнований, направленных на исполнение публичных нормативных обязательств на 2016 г., был равен 7315247 006,4 тыс. руб., т.е. целевое финансирование фонда составило 95\% [19].

Среди российских научных государственных фондов только Фонд содействия развитию малых форм предприятий в научно-технической сфере занимается выработкой рекомендаций о дальнейшем развитии проектов, работа над которыми финансировалась фондом. Отсутствие концепции стратегического развития программ фондов, направленных на поддержку исследований и разработок, приводит к фрагментарности научных исследований и снижению эффективности расходования государственных средств [1. С. 41].

Подводя итог проведенного анализа эффективности функционирования таких государственных механизмов, как фонды инновационного развития, можно отметить их достаточно низкую эффективность в части целевого использования средств, которая составляет 6-80\% против 95\%, например, у Пенсионного фонда РФ. 
В части эффективности применения инструментов воздействия на экономику можно отметить следующее. Инновационная политика реализуется через государственные целевые программы. Статьи бюджетов этих программ являются теми самыми инструментами. В последнее время наметилась тенденция распыления грантовых средств среди грантополучателей, т.е. уменьшается средний размер гранта при увеличении количества грантополучателей. Такое рассредоточение средств значительно снижает эффективность их использования конечными получателями, поскольку происходит недофинансирование проектов.

$\boldsymbol{O A O}$ «Роснано» - государственная корпорация, созданная в 2007 г. для развития нанотехнологий. Основным видом деятельности компании является инвестирование средств в частные проекты по созданию новых нанотехнологических производств.

По итогам 2015 г. группа «Роснано» показала чистую прибыль в размере 4,9 млрд руб. против убытка в 8,4 млрд руб. годом ранее. За 2015 г. доходы компании составили: 10,3 млрд руб. - доход от инвестиций в инвестиционные проекты (в основном «бумажный» доход, связанный с переоценкой портфельных инвестиций), 6,3 млрд руб. - процентный доход от депозитов и остатков по расчетным счетам. Основные виды расходов: проценты по кредитам - 14,1 млрд руб. и заработная плата - 2,8 млрд руб. Кредиты и займы на 31.12.2015 составили 149 млрд руб., что более чем в 3 раза превышает сумму размещенных депозитов на конец 2015 г. и почти в 2 раза превышает акционерный капитал «Роснано» [20].

25 апреля 2016 г. Счетная палата (СП) признала половину инвестпроектов «Роснано» неэффективными: расходы госкомпании при выходе из проектов принесли убыток в 13,1 млрд руб. По итогам проверки СП предложила изменить правила предоставления «Роснано» госгарантий и запретить выплаты руководству госкомпании вознаграждений по убыточным проектам за счет кредитов и займов по госгарантиям [15].

$\boldsymbol{B} Э \boldsymbol{Б}$ - национальный банк развития, содействующий реализации государственной социально-экономической политики, повышению конкурентоспособности национальной экономики и ее модернизации на инновационной основе.

Внешэкономбанк не является коммерческим банком, его деятельность регулируется специальным законом № 82-Ф3 «О банке развития», вступившим в силу 4 июня 2007 г. Согласно меморандуму о финансовой политике Внешэкономбанк предоставляет кредиты, гарантии и поручительства по проектам, срок окупаемости которых превышает пять лет, а общая стоимость - более 2 млрд руб.

Деятельность банка должна способствовать улучшению инвестиционного климата в Российской Федерации. ВЭБ должен стремиться к тому, чтобы для финансирования его долгосрочных инвестиционных проектов привлекались средства российского бизнеса и зарубежных партнеров, снижая их риски. Объективную оценку эффективности деятельности ВЭБ можно получить путем анализа динамики инвестиционной привлекатель- 
ности России на мировом уровне. Ежегодно международная консалтинговая компания A.T. Kearney публикует рейтинг самых привлекательных для инвестиций стран мира. Рейтинг А.Т. Kearney, или Kearney Foreign Direct Investment Confidence Index, рассчитывается по данным опроса руководителей 300 компаний, оборот каждой из которых превышает 1 млрд долл. Эти компании располагаются в 26 странах мира и представляют все индустриальные сектора. Индекс рассчитывается как средневзвешенный показатель из ответов респондентов о высокой, средней или низкой вероятности инвестиций в определенную страну в течение следующих трех лет. Так, по оценкам А.Т., Россия не вошла в 25 самых привлекательных для инвесторов стран мира в 2014 г., несмотря на то, что в 2013 г. занимала 11-е место. Рейтинг за 2015 и 2016 гг. той же консалтинговой компании A.T. Kearney показывает, что Россия опять не вошла в этот список. Последний раз страна попадала в этот рейтинг в 2013 г.

Подводя итоги вышеизложенного, необходимо отметить, что в РФ сформированы практически все необходимые государственные институты развития. Однако, несмотря на их наличие, а также высокий инновационный потенциал населения, реального перехода к инновационной экономике не происходит. Анализ ситуации показывает, что основным сдерживающим фактором является высокая степень коррупции на разных уровнях власти и чиновничьего аппарата.

Фондами инновационного развития происходит распыление государственных средств, выделенных на поддержку приоритетных проектов, а также нецелевое их использование. Например, Фонд Бортника перешел к предоставлению микрогрантов с 2016 г. Как показывает практика, такое распыление инвестиционных средств неэффективно.

Фонд «Сколково» выделяет более крупные гранты - до 300 млн руб. Однако, по данным Счетной палаты РФ, здесь велика коррупционная составляющая - значительная доля грантов распределяется между экспертами и членами грантового комитета.

Кроме того, фонды злоупотребляют нецелевым использованием бюджетных средств. Велика доля собственных расходов фондов на содержание административно-управленческого аппарата. Вместо инвестиций в приоритетные проекты значительная доля прибыли фондов образуется за счет размещения средств на депозитах коммерческих банков, что не способствует развитию инновационного сектора экономики.

Считаем, что для повышения эффективности функционирования фондов развития необходимо лимитировать долю средств фонда, затрачиваемых на собственные нужды, в размере 5-10\% от общего бюджета фонда. Кроме того, передать право определения приоритетных проектов независимым экспертам, а за фондом сохранить функции консультирования и продвижения проекта. Финансирование проектов осуществлять по региональному принципу, главными целевыми показателями которого будут являться средний доход на душу населения и объем ВВП на душу населения. Основной задачей фондов должно быть обеспечение одинаково высо- 
кого уровня качества жизни населения среди различных субъектов РФ. Это должно гарантировать снижение влияния таких негативных факторов на экономику, как трудовая миграция, социальная напряженность, высокий уровень безработицы, дотационность регионов и т.п. [3].

Кроме того, среди прочих проектов, поддерживаемых фондами развития, приоритетом должны пользоваться те, которые направлены на развитие транспортно-логистической инфраструктуры страны. Это обусловлено географическими особенностями РФ - разнообразным ландшафтом, климатом и большими расстояниями [9].

\section{Литература}

1. Экономика и промышленная политика: теория и инструментарий / под ред. А.В. Бабкина. СПб. : Изд-во Политехн. ун-та, 2014. 622 с.

2. Сумина Е.В., Белякова Г.Я. Механизм формирования инновационных преимуществ региона // Фундаментальные исследования. 2015. № 8 (ч. 1). С. 210-214.

3. Абрамов P.A. Механизмы реализации инновационного развития регионов: российский и зарубежный опыт // Международный журнал прикладных и фундаментальных исследований. 2015. № 9 (ч. 2). С. 333-336.

4. Восканов М.Э. Необходимость и институциональные особенности перехода инновационной экономики к экономике знаний // Инновационное развитие экономики. 2017. № 3 (39). С. 7-11.

5. Литвиненко И.Л. Региональная инновационная система: структура и инструменты управления. М. : РУСАЙНС, 2016. 192 с.

6. Никонова Я.И. Инновационная политика развития экономических систем: методология формирования и механизм реализации // Международный журнал экспериментального образования. 2015. № 2 (ч. 2).

7. Анисимов А.М., Руденко Е.А. Запуск долгосрочного экономического роста методом структурного маневра в национальном хозяйстве РФ // Проблемы современной экономики: евразийский международный научно-аналитический журнал. 2017. № 2 (62). C. 26-32.

8. Данилина М.В., Щербакова К.С. Анализ инновационной политики Российской Федерации на современном этапе // Гуманитарные научные исследования. 2014. № 10. URL: http://human.snauka.ru/2014/10/7918 (дата обращения: 26.05.2017).

9. Логинова Е.В., Миреикий И.Ю., Попов П.В. Роль инфраструктурных факторов в обеспечении экономического роста // Тренды и управление. 2016. № 4. С. 410-418. DOI: 10.7256/2307-9118.2016.4.21133.

10. Саленко Т.В. Основные направления реализации государственной инновационной политики в России // Научно-методический электронный журнал «Концепт». 2016. T. 2. C. 561-565. URL: http://e-koncept.ru/2016/46130.htm

11. Официильный сайт AO «PBK». URL: http://www.rvc.ru/ (дата обращения: 13.09.2017).

12. РwC Россия : сайт Международной консалтинговой сети. Пресс-центр. Прессрелиз за 2016 год. URL: http://www.pwc.ru/ru/press-releases/2016/money-tree.html (дата обращения: 10.09.2017).

13. Официальный сайт РИА новости - информационное агентство. URL: http://ria.ru/sk_analytics/20120130/552435125.html?ria=n44mcmg4c6q3v01t9trglf6lo9 (дата обращения: 11.08.2017).

14. Инновационный центр Сколково : сайт. URL: https://startupvillage.ru/en/schedule (дата обращения: 11.08.2017). 
15. Светлана Бочарова. Счетная палата пожаловалась на «Сколково» в Генпрокуратуру // «РосБизнесКонсалтинг»: Экономика. 02.10.2016. URL: http://www.rbc.ru/ economics/02/10/2016/57f10aa99a79474c0282a5e7 (дата обращения: 12.08.2017).

16. Постановление Правительства Российской Федерации от 3 июля 2012 года № 680 «Об уставе федерального государственного бюджетного учреждения «Фонд содействия развитию малых форм предприятий в научно-технической сфере» (с изменениями на 29 августа 2017 года) // Консорциум «КОДЕКС»- электронный фонд правовой и нормативно-технической документации. URL: http://docs.cntd.ru/ document/ 902356068 (дата обращения: 13.08.2017).

17. Отчет Фонда содействия развитию малых форм предприятий в научнотехнической сфере за 2015 год. URL: http://www.fasie.ru/upload/docs/ (дата обращения: 13.08.2017).

18. Отчет Фонда содействия развитию малых форм предприятий в научнотехнической сфере за 2014 год. URL: http:/www.fasie.ru/upload/docs/ Annual_Report\%202014.pdf (дата обращения: 13.08.2017).

19. Пенсионный фонд РФ: официальный сайт. URL: http:/www.pfrf.ru/info/order/ budzhet_pfr/ 2795 (дата обращения: 15.08.2017).

20. Финбаза: сайт. База отчетностей. URL: http://www.finbaza.com/singlepost/5764796f0cf26813fb97ef8b (дата обращения: 16.08.2017).

21. Счетная палата РФ. Отчет о результатах контрольного мероприятия «Проверка использования средств федерального бюджета, направленных на реализацию мероприятий, связанных с созданием и обеспечением функционирования инновационного центра «Сколково» в 2013-2015 годах» (совместно с Федеральной службой безопасности Российской Федерации). URL: http://audit.gov.ru/upload/iblock/7ef/7ef719e25a 1211b0405dd4efdf9e9041.pdf

Bekov R.B., Senior Lecturer of the Management Chair at the Dagestan State University of National Economy (Makhachkala, Russian Federation), co-curator on the IBA program "Business Management" at the International Business School of the Dagestan State University of National Economy (Makhachkala, Russian Federation). E-mail: bekov.rusik@yandex.ru

\section{EFFICIENCY OF MECHANISMS OF INNOVATIVE DEVELOPMENT OF THE} RUSSIAN ECONOMY

Keywords: World Economic Forum; global competitiveness index; Agency for Strategic Initiatives; Vnesheconombank; Skolkovo Foundation; innovative development of the economy; efficiency; investments.

The article considers the main state development institutions in the Russian Federation, responsible for innovation implementation processes and technological modernization of the economy. The expert estimation of economic condition of Russia is resulted on results of work of the largest International economic forums of 2016 in Davos and St.-Petersburg taking into account world trends and challenges. Also an assessment of the current state of the investment attractiveness of the Russian economy is given. The place of the Russian Federation in the ranking of global competitiveness is determined.

The author analyzed the activities of state development institutions, such as the Federal Agency for Strategic Initiatives, JSC "Russian Venture Company", OJSC "Rusnano", Vnesheconombank. Comparative analysis of economic and social efficiency of innovative development funds is given. In particular, the activities of the Skolkovo Foundation and the Foundation for Assistance to Small Innovative Enterprises in the scientific and technical sphere are considered.

Based on the results of the analysis, some recommendations for improving state mechanisms for innovative development are given. 


\section{References}

1. Ekonomika i promyshlennaya politika: teoriya i instrumentarij/ pod red. dok. ehkon. nauk, prof. A.V. Babkina. - SPb.: Izd-vo Politekhn. un-ta, 2014. - 622 s.

2. Sumina E.V., Belyakova G.YA. Mekhanizm formirovaniya innovacionnyh preimushchestv regiona // Fundamental'nye issledovaniya. M.: ID «Akademiya Estestvoznaniya», 2015. № 8 (chast' 1). S. 210-214.

3. Abramov R.A. Mekhanizmy realizacii innovacionnogo razvitiya regionov: rossijskij i zarubezhnyj opyt // Mezhdunarodnyj zhurnal prikladnyh i fundamental'nyh issledovanij. M.: ID «Akademiya Estestvoznaniya», 2015. № 9 (chast' 2). S. 333-336.

4. Voskanov M.EH. Neobhodimost' i institucional'nye osobennosti perekhoda innovacionnoj ehkonomiki k ehkonomike znanij // Innovacionnoe razvitie ehkonomiki. Nauchnoprakticheskij i teoreticheskij zhurnal. Joshkar-Ola: OOO IPF «STRING», 2017. № 3 (39). S.7-11.

5. Regional'naya innovacionnaya sistema: struktura i instrumenty upravleniya: monografiya / I.L. Litvinenko. M.: RUSAJNS, 2016. $192 \mathrm{~s}$.

6. Nikonova YA.I. Innovacionnaya politika razvitiya ehkonomicheskih sistem: metodologiya formirovaniya i mekhanizm realizacii (monografiya) // Mezhdunarodnyj zhurnal ehksperimental'nogo obrazovaniya. M.: ID «Akademiya Estestvoznaniya», 2015. № 2 (chast' 2) S. 274-275.

7. Anisimov A. M., Rudenko E. A. Zapusk dolgosrochnogo ehkonomicheskogo rosta metodom strukturnogo manevra v nacional'nom hozyajstve RF // Problemy sovremennoj ehkonomiki. Evrazijskij mezhdunarodnyj nauchno-analiticheskij zhurnal, N 2 (62), 2017. S. 26-32.

8. Danilina M.V., SHCHerbakova K.S. Analiz innovacionnoj politiki Rossijskoj Federacii na sovremennom ehtape // Gumanitarnye nauchnye issledovaniya. 2014. № 10 [EHlektronnyj resurs]. URL: http://human.snauka.ru/2014/10/7918 (data obrashcheniya: 26.05.2017).

9. Loginova E.V., Mireckij I.YU., Popov P.V. Rol' infrastrukturnyh faktorov v obespechenii ehkonomicheskogo rosta // Trendy i upravlenie. M.: OOO «NB-Media», 2016. № 4. S. 410-418. DOI: 10.7256/2307-9118.2016.4.21133.

10. Salenko T.V. Osnovnye napravleniya realizacii gosudarstvennoj innovacionnoj politiki v Rossii // Nauchno-metodicheskij ehlektronnyj zhurnal «Koncept». - Kirov: ANO DPO «MCITO», 2016. - T. 2. - S. 561-565. - URL: http://e-koncept.ru/2016/46130.htm.

11. Oficial'nyj sajt AO «RVK». URL: http://www.rvc.ru/ (data obrashcheniya: 13.09.2017).

12. PwC Rossiya. Sajt Mezhdunarodnoj konsaltingovoj seti. Press-centr. Press-reliz za 2016 god. URL: http://www.pwc.ru/ru/press-releases/2016/money-tree.html (data obrashcheniya: 10.09 .2017$)$.

13. Oficial'nyj sajt RIA novosti - informacionnoe agentstvo. URL: http://ria.ru/sk_analytics/20120130/552435125.html?ria=n44mcmg4c6q3v01t9trglf6lo9 (data obrashcheniya: 11.08.2017).

14. Innovacionnyj centr Skolkovo. Sajt. URL: https://startupvillage.ru/en/schedule (data obrashcheniya: 11.08.2017).

15. Svetlana Bocharova. Schetnaya palata pozhalovalas' na «Skolkovo» v Genprokuraturu // $\quad$ «RosBiznesKonsalting»: $\quad$ EHkonomika, 02.10.2016. URL: http://www.rbc.ru/economics/02/10/2016/57f10aa99a79474c0282a5e7 (data obrashcheniya: 12.08.2017).

16. Postanovlenie Pravitel'stva Rossijskoj Federacii ot 3 iyulya 2012 goda N $680 \ll \mathrm{Ob}$ ustave federal'nogo gosudarstvennogo byudzhetnogo uchrezhdeniya «Fond sodejstviya razvitiyu malyh form predpriyatij v nauchno-tekhnicheskoj sfere»») (s izmeneniyami na 29 avgusta 2017 goda) // Konsorcium «KODEKS» - ehlektronnyj fond pravovoj i normativnotekhnicheskoj dokumentacii. URL: http://docs.cntd.ru/document/902356068 (data obrashcheniya: 13.08.2017). 
17. Otchet Fonda sodejstviya razvitiyu malyh form predpriyatij v nauchno-tekhnicheskoj sfere za 2015 god. URL: http://www.fasie.ru/upload/docs/ (data obrashcheniya: 13.08.2017).

18. Otchet Fonda sodejstviya razvitiyu malyh form predpriyatij v nauchno-tekhnicheskoj sfere za 2014 god. URL: http://www.fasie.ru/upload/docs/Annual_Report\%202014.pdf (data obrashcheniya: 13.08.2017).

19. Pensionnyj fond RF. Oficial'nyj sajt. URL: http://www.pfrf.ru/info/ order/budzhet_pfr/ 2795 (data obrashcheniya: 15.08.2017).

20. Finbaza. Sajt. Baza otchetnostej. URL: http://www.finbaza.com/singlepost/5764796f0cf26813fb97ef8b (data obrashcheniya: 16.08.2017).

21. Schetnaya Palata RF. Otchet o rezul'tatah kontrol'nogo meropriyatiya «Proverka ispol'zovaniya sredstv federal'nogo byudzheta, napravlennyh na realizaciyu meropriyatij, svyazannyh s sozdaniem i obespecheniem funkcionirovaniya innovacionnogo centra «Skolkovo» v 2013-2015 godah» (sovmestno s Federal'noj sluzhboj bezopasnosti Rossijskoj Federacii) [EHlektronnyj resurs]. URL: http://audit.gov.ru/upload/iblock/ 7ef/7ef719e25a1211b0405dd4efdf9e9041.pdf

\section{For referencing:}

Bekov R.B. Effektivnost' mekhanizmov innovacionnogo razvitiya ehkonomiki RF [Efficiency of mechanisms of innovative development of the Russian economy] Vestnik Tomskogo gosudarstvennogo universiteta. Ekonomika - Tomsk State University Journal of Economics, 2018, no 42, pp. 246-258. 